\title{
Hemocyte Encapsulation of Streptococci in Drosophila
}

\author{
T. M. RIZKI \\ Department of Zoology, The University of Michigan, \\ Ann Arbor, Michigan 48104
}

Received April 1, 1968

\begin{abstract}
Electron micrographs of infectious bacterial cells encapsulated by hemocytes in Drosophila suggest that bacterial lysis within the capsular confines may be the mode of the hemocyte defense reaction rather than intracellular phagocytic destruction.
\end{abstract}

Larvae with melanotic masses were noted in several culture dishes during routine collection of eggs and larvae of Drosophila melanogaster. These dishes contained the progeny of the dumpy $(d p)$ mutant, and affected larvae continued to appear for 5 successive days of egg collection from the same group of parents. The melanotic masses were localized in the anterior region of the larva as shown in a typical example (Figs. 1 and 2), and dissection of larvae revealed that the melanotic masses consisted of blood cells and encapsulated bacteria (Fig. 3). This unusual occurrence of an apparently infectious bacterium in Drosophila provided an excellent opportunity to examine the hemocyte response and its effectiveness at the level of ultrastructural detail. Several capsules were therefore removed from larvae and fixed in formalin for electron microscopy. Following postfixation in osmium, the nodules were embedded in Epon and sections stained with uranyl acetate followed by lead citrate.

1 The author wishes to express his appreciation to Professor D. Merchant of the Department of Microbiology, University of Michigan, for suggestions concerning the culture of the microbes as well as help in identifying this microorganism, and to Miss Sandra Erickson for technical assistance. This work was supported by a research grant from the National Science Foundation (GB-4581) and funds from the Institute of Science and Technology of the University of Michigan.
The lamellocyte variant of the blood cells served as the mode of encapsulation of the bacterial cells and the phenomenon of encapsulation thus resembles that described for the hereditary melanotic strains of Drosophila, tumor ${ }^{*}$ and melanotic tumor ${ }^{A}$ (Rizki, 1957, 1962), and the defense reaction of Drosophila against eggs and larvae of Pseudeucoila bochei (Walker, 1959). A section through the central portion of the capsule reveals a high density of single cocci as well as some cocci undergoing cell division (Figs. 6 and 8). Many of the bacterial walls appear swollen and these bacteria tend to be located generally near the periphery close to the encapsulating hemocytes. No evidence of phagocytosis of bacteria or bacterial inclusions was detected within the hemocytes. Bacterial destruction is occurring in the capsules, however, suggesting that secretion of lytic factors by the hemocytes may play a role in combating the infection. This suggestion is further supported by the appearance of some of the cocci (Fig. 7) which resemble "protoplasts" or osmotically sensitive forms of bacteria converted by leukozyme $\mathrm{C}$ and lysozyme (Amano et al., 1956).

Rupture of a single capsule yielded a rich supply of cocci (Fig. 5). Melanotic masses were therefore removed from several larvae, rinsed in sterile medium, and transferred to both tryptone agar and tryptone broth 

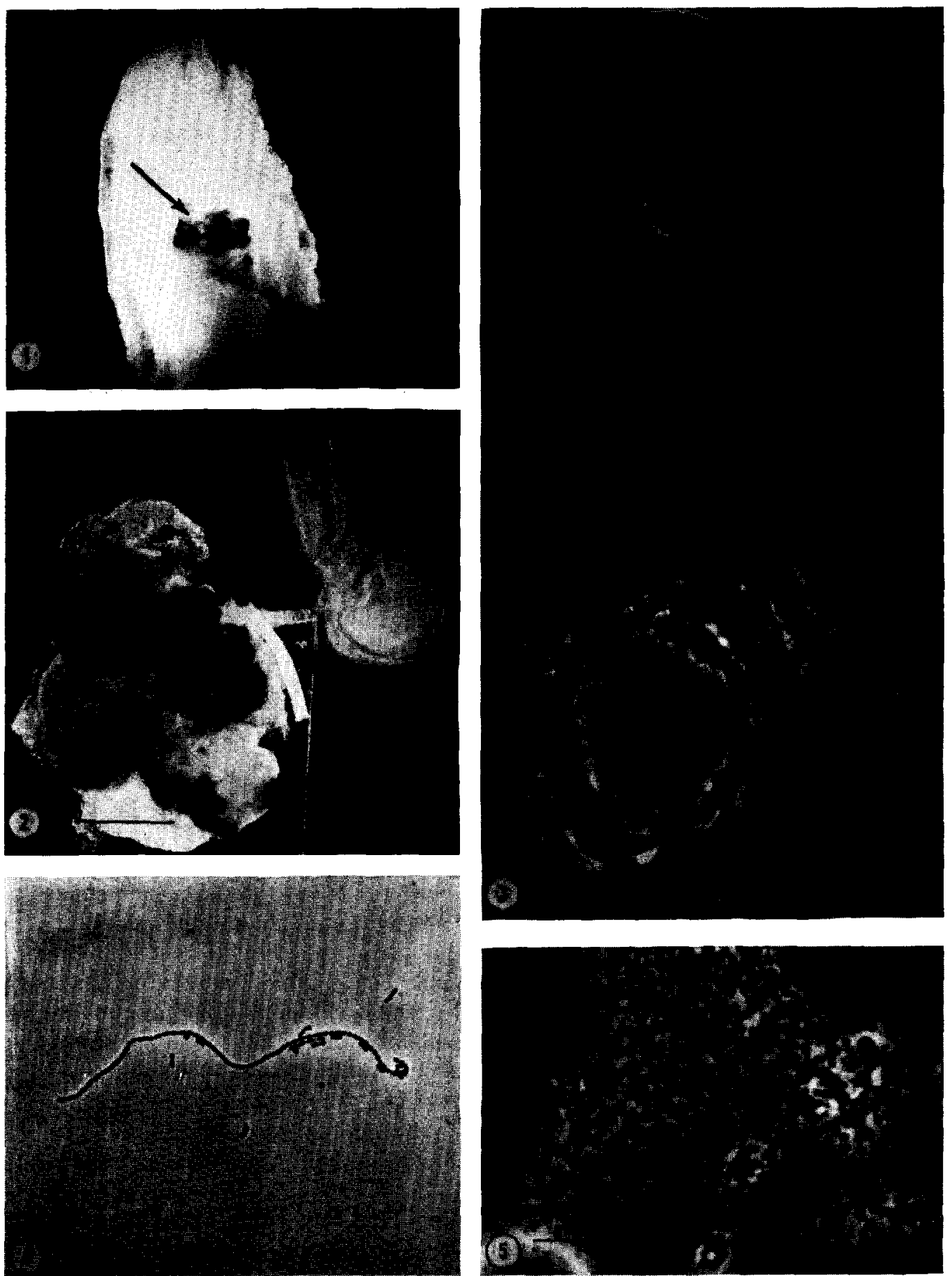

Fig. 1. The location of a melanotic mass (arrow) in the anterior region of the body of a larva of Drosophila melanogaster.

FIG. 2. The same melanotic mass pictured in Fig. 1 removed from the larva. Note the nodular appearance of the encapsulated masses of bacteria. This photograph also shows the haltere imaginal disk attached to the main tracheal trunk to which the tumorous mass is also attached. Some of the imaginal disks underlying the melanotic mass have been destroyed by this process. Scale $0.1 \mathrm{~mm}$.

Fic. 3. A section showing the encapsulating blood cells (lamellocyte variant) and the bacteriafilled nodule: L, lamellocyte; $N$, nucleus with dark contrasting nucleolus; $B$, bacteria; $M$, melanin de- 
posits. This photograph of a thin section prepared for electron microscopy was taken under the phase microscope. Scale $50 \mu$.

Fig. 4. Phase-contrast photograph of bacteria grown in liquid culture medium, illustrating the extent of chain formation. Asynchrony of the bacteria in division is evident, and most of the bacteria at one end of the chain are in division whereas at the other end of the same chain, the cocci have completed division. Scale $10 \mu$.

Fig. 5. Phase-contrast photograph of bacteria released by rupturing the nodules in Ringer solution. Both single bacterial cells and double coccal forms are found. Scale $10 \mu$.

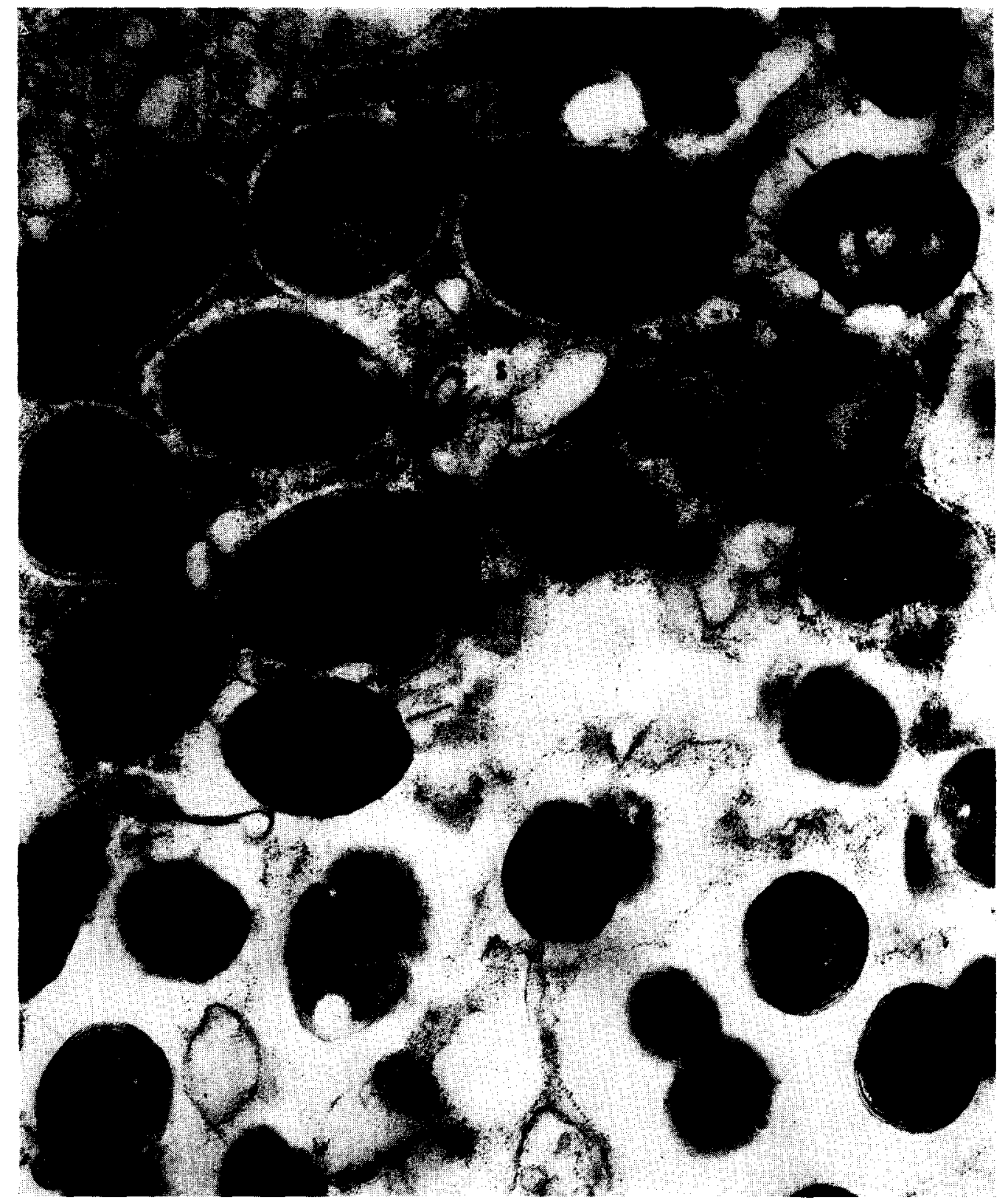

Fig. 6. An electron micrograph of the encapsulated bacteria within the nodule. Note the swollen bacterial cell walls of the cells located near the periphery, $S$; the cytoplasm of these cocci is highly granular and some are badly distorted, most likcly being destroycd. Those in division (labeled X) have a very different appearance of the cytoplasm and cell wall. P, Periphery of the capsule; H, cytoplasm of the hemocyte. 

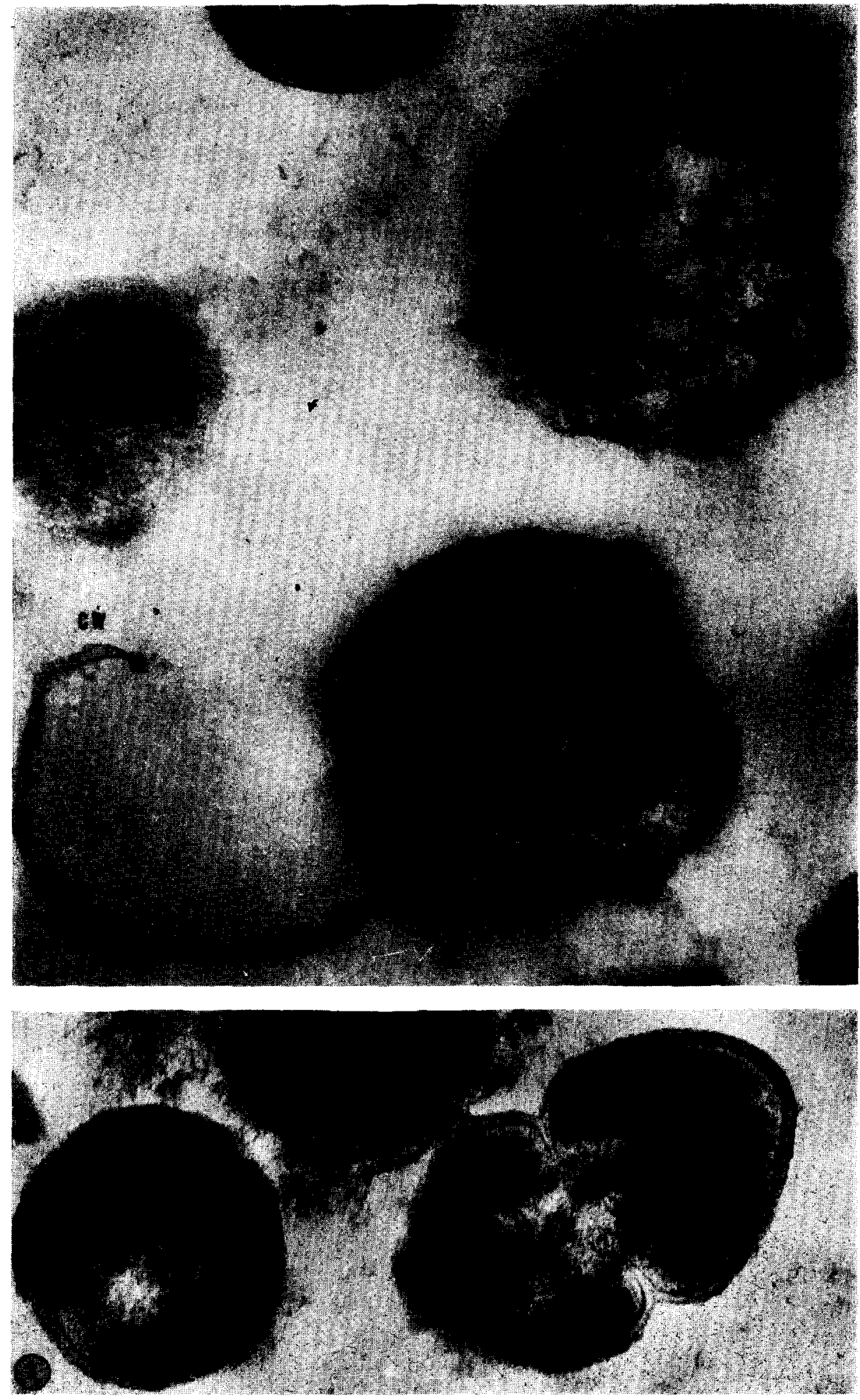

Fis. 7. Bacteria within the nodule illustrating the disruption of the cell wall ( $\mathrm{CW}$ ) leading to the "protoplast" appearance. $120,000 \times$.

FIG. 8. Details of a dividing coccus showing cell wall formation. Note the difference in appearance of cell protoplasm enclosed within the cell wall and the protoplast in Fig. 7. The ribosomes $(R)$ of the cells with swollen membranes create a granular appearance in contrast to smoother pattern noted in the dividing cell. Refer to the cells in Fig. 6 marked S. 120,000 $\times$. 
where the capsules were broken. Bacterial growth was supported on this medium, and in older cultures, long chains of what was identified as Streptococcus were common (Fig. 4). Reinfection of larvae was demonstrated by adding the bacteria to Drosophila cultures. Mortality of the infected individuals occurred primarily in the pupal stage. Several dead larvae were found, but the lethal effects of the infection appeared to be a property of the site of the infection since the large melanotic inclusions in the anterior region of the body hindered the development and eversion of the major thoracic imaginal disks during the early pupal period. Only two female adults with melanotic masses survived from a group of 36 infected pupae, and attempts to breed these individuals were unsuccessful.

After several months of growth in culture, the bacteria were seeded on culture medium in which larvae were growing. Melanotic masses were no longer obtained by this procedure. It appears probable that the original infective variant of this Streptococcus produced some chemical signal which caused the hemocytes to act as a selective agency operating against it. However, the progeny of the original infective form lack this facility and the isolated forms are no longer pathogenic. Loss of infectivity may be due to selective forces under the conditions imposed by culture. The possibility exists that lysogeny of bacteria may play a role in pathgenesis and the infective bacterial form is related to the presence of a prophage. A well-known example of such a relationship between pathogenicity and lysogeny is the modification in production of toxin by Corynebacterium diptheriae (Adams, 1959).

\section{Refertences}

Anans, M. H. 1959. "Bacteriophages," 446 pp. Interscience, New York.

Amano, T., Seki, Y., FujlKawa, K., Kashiba, S., Monioka, T., AND ICHIKAwa, S. 1956. The isolation and characterization of protoplast from Escherichia coli B with treatment of leucocyte extracts. Med. J. Osaka Univ., 7, $245-256$.

Rizki, T. M. 1957. Tumor formation in relation to metamorphosis in Drosophila melanogaster. J. Morphol., 100, 459-472.

Rizki, T. M. 1962. Experimental analysis of hemocyte morphology in insects. Am. Zoologist, 2, 247-256.

WALker, I. 1959. Die Abwehrreaktion des Wirtes Drosophila melanogaster gegen die zoophage Cynipide Pseudeucoila bochei Weld. Rev. Suisse Zool., 66, 559-632. 